・保护论坛・

\title{
我国自然保护区资金机制改革创新的几点思考
}

\author{
沈兴兴*马忠玉 曾贤刚
}

(中国人民大学环境学院, 北京 100872)

\begin{abstract}
摘要: 目前国际上自然保护地的资金投入规模远远低于实际需求，未来融资机制需要创新，包括吸引和利用外部 资金、鼓励自行经营创收、基于保护地产品或服务的市场交易收费等, 其中鼓励创收主要指的是财政手段(例如生 态税)、收益共享机制、管理成本共担机制、金融交易(例如碳排放交易)等。政治领域的制度规范、经济领域的市 场、价格政策等都会影响保护地的融资机制，保护地未来的融资机制将更多地依赖于财政、金融、市场、贸易相 互结合的多元化融资手段。我国自然保护区目前存在资金来源结构不合理、资金规模太小, 支出结构不合理、缺 乏周边社区补偿和收益共享机制等问题。为此，作者提出以下建议：(1)确保中央财政承担国家级自然保护区的主 要管理经费; (2)在充分发挥生态旅游服务付费、资源使用付费等传统产品(服务)收费型融资手段的基础上，建立和 完善生态系统服务付费、森林碳汇交易和保护区绿色产品认证等新的市场交易型融资渠道; (3)利用境外资金提升 我国自然保护区的能力建设; (4)积极争取国内不同社会团体的资金支持, 条件允许的保护区可通过多方联合治理 模式建立管理成本共担机制以及与周边社区的收益共享机制。(5)在资金使用方面，在保障保护区工作人员基本薪 酬福利的前提下，将剩余资金包括经营收入优先用于核心保护业务的投资上，同时加强资金的监管。
\end{abstract}

关键词：融资机制，融资渠道，资金的使用和分配

\section{Reflections on innovative funding mechanisms for nature reserves in China}

Xingxing Shen ${ }^{*}$, Zhongyu Ma, Xiangang Zeng

School of Environment and Natural Resources, Renmin University, Beijing 100872

\begin{abstract}
The funding scale invested in protected areas is far lower than funding needed. Innovative financing mechanisms in the future will involve seeking external funds, self generating and retaining revenues, and charging fee systems based on products or service markets. Generating revenue refers to fiscal approaches like ecological taxes, benefits and cost sharing mechanisms, and financial trades like carbon trading, etc. The political institutions and regulations as well as market or price policies both affect the financing mechanisms of protected areas. In the future, the financing mechanisms for protected area will depend on diversified financing channels covering fiscal, finance, market and trade tools. The concept of sustainable financing for protected areas mainly refers to the capacities of obtaining abundant, stable and long-term financial resources as well as allocating these financial resources in a timely and appropriate manner, so as to cover the full cost and achieve conservation objectives for protected areas. The major problems of the current funding mechanism and expenditure status of Chinese nature reserves include the unreasonable structure of funding sources and funds expenditure, low levels of funding amounts, as well as the lack of compensation and benefit sharing with the local community. This paper suggests ensuring federal fiscal sources as the dominant funding source for national nature reserves and establishing or improving the new market and trading channels such as PES (Payment for Ecosystem Service), carbon trade and green product certification (based on the traditional charging system including payment for eco-tourism services and resources using fees). In addition, we suggest using overseas funds as much as possible to promote capacity building of Chinese nature reserves and trying to raise funds from different domestic societies. Moreover, multi-stakeholders shared governance could be piloted in some nature reserves to achieve cost sharing among key stakeholders and benefit sharing
\end{abstract}

收稿日期: 2015-04-28; 接受日期: 2015-06-29

基金项目: 国家社会科学研究基金重大项目“生态产品的供给机制与制度创新研究”(13\&ZD045)

“通讯作者 Author for correspondence. E-mail: xingxinghenry@126.com 
mechanisms between local communities and the nature reserves. The authors also suggest that the majority of funds should be spent on conservation investments after the necessary staff salary deduction.

Key words: financing mechanism, financing sources, funds using and allocation

\section{1 保护地的内涵及分类}

世界自然保护联盟(IUCN)将保护地定义为: 为 了实现自然资源和相关生态系统服务、文化价值的 长久保护, 通过法律或其他有效途径得到明确界 定、许可、投入和管理的特定地理区域(Dudley, 2008)。按照IUCN对于保护地的分类(Dudley, 2008), 我国目前的自然保护区大多按照第一类严格的自 然保留区(Ia)管理。实际上我国部分自然保护区可 以归为IUCN保护地类型的后几类，如国家公园等。 近期我国正在探讨建立国家公园体制, 如果借此机 会重新梳理和规范我国的保护地分类体系, 将是非 常有益的。

自1872年世界上第一个国家公园一一美国黄 石国家公园建立至今，世界上已有200多个国家和 地区建立了不同类型的保护地，保护地的面积从 1962 年的 240 万平方公里, 增加到 2004 年的 2,000 万 平方公里，大约占到全球地表面积的 $12 \%$ (Chape, 2005)。然而, 很多保护地的管理质量和保护效果不 容乐观，其中资金投入不足是影响保护地管理目标 实现的一个关键因素(Ervin, 2003; Hockings et al., 2006)。2003年第五次IUCN世界公园大会和2004年 的《生物多样性公约》第七次缔约方大会上都强调 了投资不足是生物多样性保护的普遍问题, 尤其针 对保护地的投资特别缺乏, 号召对保护地传统的融 资手段进行创新，确保全球、国家和区域层面生物 多样性保护状况的改善。因此, 了解国际上自然保 护地的融资机制发展现状和趋势, 借鉴国际经验为 我国自然保护区的融资机制、资金机制提出相应的 对策和建议, 对促进我国自然保护区的可持续管理 和生物多样性保护具有重要意义。

\section{2 国际上保护地的融资现状}

\section{1 资金数量}

当前全球对保护地的净投入水平普遍无法满 足实际需求, 据联合国开发计划署(UNDP)一项研 究, 在占地球生物多样性总量约 $40 \%$ 的拉丁美洲和 加勒比海地区, 每年保护地要达到基础管护目标还
有3.14亿美元的资金缺口，而如果达到高度有效管 理则有7亿美元的缺口(UNDP, 2012)。资金不足这一 问题在发展中国家更为严重, 在发展中国家只有 $34 \%$ 的保护区管理经费需求得到满足。据估计未来 10 年, 每年需要额外的 120-130亿美元来支持发展 中国家扩大和管理其保护地系统 (Bruner et al., 2004; Chape et al., 2003)。因此, 为保护地寻找新的 资金来源是非常迫切的问题。

\section{2 资金来源}

(1)政府财政预算。虽然非政府和私人的资助在 保护区融资中的比重越来越大, 但由于大多数国家 的保护地主要由政府管理，所以政府财政预算资金 (Cousins et al., 2010; Lapham \& Livermore, 2003)仍 然是保护区融资的主要来源。例如, 加拿大国家公 园预算的 $83 \%$ 来自政府拨款; 美国国家公园的资金 主要来自联邦财政, 每年的联邦财政投入大概 24 亿 美元，约 $8 \%$ 来自使用者收费，社会捐助占 $1 \%$, 志愿 者支持大约占 $3.3 \%$ (Molnar et al., 2004)。

(2)国际援助。双边或多边援助机构捐赠资金是 保护地融资的第二个重要来源, 通常也是很多发展 中国家保护地领域政府预算之外的最主要资金来 源。多边援助机构, 如联合国的机构、世界银行、 亚洲开发银行、欧盟等; 双边援助机构, 如加拿大 发展援助署、澳大利亚发展援助署、荷兰政府等。 此外，还有来自世界自然基金会(WWF)、美国大自 然保护协会(TNC)、世界自然保护联盟等国际非政 府组织(NGO)的捐赠。双边和多边的捐赠机构在 1990-1997年向拉丁美洲和加勒比海国家的生物多 样性保护总共捐助了超过 30 亿美元，大约 $1 / 3$ 的资 金都是直接投给保护地的建设和管理(Castro \& Locker, 2003)。

(3)社会群体和私人捐助。保护地资金的私人来 源主要包括企业和慈善基金会以及非政府组织和 当地的社团。虽然这些资金中一部分来自政府和大 型基金会，但也有相当一部分资金是来自公众的私 人捐赠。例如WWF荷兰分会的绝大部分资金都来 自会员每年的会费捐赠。此外，还包括小企业、私 人土地所有者和当地社区等的资助，目前还很难去 
统计具体数额。最近的一项研究推测, 目前全球尺 度上社区在森林保护上的投入规模与发展中国家 公共保护地每年的支出相当(Molnar et al., 2004)。

（4)基于市场交易的收费。资源使用付费和生态 旅游收费已经成为很多国家保护地资金的一个重 要来源。印度尼西亚Bunaken国家公园的门票收入 从 2001 年的 4.2 万美元提高到 2007 年的 15.5 万美元。 2007年肯尼亚野生动物服务管理局共收取了 2,800 多万美元的保护地门票费, 相当于该管理局运营费 用的68\%(UNDP, 2012)。很多发达国家保护地内的 特许经营收入在保护地资金总量中也占有越来越 大的比重: 研究表明美国州立公园1984年运营收入 的使用者付费占到 $38 \%$ ，而 2004 年则提高到 $46 \%$ (Landrum, 2005); 加拿大安大略公园系统包括329 个省级公园，2007年公园预算大约 $80 \%$ 都来自旅游 收入。

\section{3 保护地资金的使用和分配}

\section{1 保护地管理的全成本}

保护地融资传统意义上侧重用于直接的运行 和管理费用, 即建立和运行保护地所需的人员工 资、基础设施、设备和维护。然而, 真正意义上的 保护地全成本还应包括保护地对周围社区造成的 间接和机会成本, 例如禁止资源利用或者放弃的其 他土地用途所产生的成本, 以及被迫放弃开采利用 林木产品等传统生计方式所带来的成本等。这些间 接成本和机会成本通常很大, 涉及的群体也很广, 包括当地土地所有者和资源使用者, 以及公众和私 人企业和其他部门。在全球尺度上, 为了保护生态 系统多样性, 每年因限制土地利用的机会成本估计 在 455-1,438 亿美元之间 (Lewandrowski et al., 1999)。然而很少保护地将这部分资金列入其主要 预算。

经济学上保护地的可持续就包含所有这些间 接成本和机会成本, 并对承担这些成本的群体进行 补偿。如果在融资需求里面没有考虑这些成本, 会 导致承担这些成本的群体不愿意支持保护区的管 理, 直接影响到保护地的可持续和管理的有效性。

\section{2 保护地财务的可持续}

很多国家的政府财政预算是保护区资金的唯 一来源, 还有些国家的保护地旅游参观的收入是保 护地资金最主要的组成部分。然而仅仅依赖一个或
少数资金来源是有风险的, 并且容易受到通胀、社 会安全等因素的影响。多样化的融资组合可以更好 地帮助保护地管理者应对财务风险。

因此，“保护地财务可持续”可以理解为: 为了 承担保护地的全部成本以及全面实现保护目标，能 够获得充足、稳定和长期的财务资源，并及时、合 理地分配这些财务资源的能力。保护地财务可持续 不仅需要及时获取资金, 而且资金使用和分配的方 式要能支持长远的保护目标; 不仅要承担保护地的 直接和间接成本, 还要关注保护地的收益及其在不 同利益群体之间的分配。在绝大多数发展中国家, 这又意味着保护地在摆脱贫困中的作用。此外, 增 加保护地融资的自主性(如自主经营获取收入的机 会)也有助于实现保护地的财务可持续。

\section{4 保护地融资机制的创新及存在的问题}

为了解决保护地资金投入不足问题, 有必要对 传统的以财政拨款为主的融资机制进行改革创新。 目前的创新机制主要包括以下 3 个方面:

\section{1 吸引和利用外部资金}

外部资金主要包括政府、NGO赠与、私人和自 愿捐助、环境基金和债务自然环境互换(debt-fornature swaps)等国际和国内资金来源。其中“债务环 境交换机制”是一种金融创新模式，它指的是免去 一个发展中国家的对外债务, 条件是该国家将这部 分资金投入到本国的自然保护或环境保护领域。从 1987年开始的近30年内, 通过这种自然债务互换在 发展中国家已经募集了10亿美金的环境基金 (Adrian, 2000)。

\section{2 鼓励自行经营创收}

保护地的融资经常受到所在国政治、经济环境 的影响, 例如有些国家法律上不允许保护区自行创 收, 也不允许在有限范围内的经营创收活动, 这就 需要进行制度层面的改革创新。为了给保护地寻求 更多的资金支持，应该鼓励保护地的自行创收活动 并反哺保护。主要有4种类型的创收手段(Emerton et al, 2006):

(1)财政手段。通过提高环境破坏行为的成本 (例如征收环境税、费)或者提高环境友好行为的回 报(补贴), 以达到更有效地使用资源和减少污染。例 如通过环境收费和财政转移支付筹集环境保护和 自然资源管理的资金; 同时通过公共投资和价格改 
革改善环境公共产品的获取途径, 以确保环境资源 管理成本和效益分配的合理性和公平性。值得提醒 的是需要取消一些不合理的财政补贴,一些国家的 财政补贴使得破坏生物多样性的成本与保护地的 投入相比更低, 就会增加保护地的机会成本。

(2)收益和收入共享机制。收益和收入共享机制 是保护地领域极具潜力的一个融资渠道。从 20 世纪 80 年代早期开始就强调将周边社区纳入保护地管 理, 确保社区从生物多样性保护中受益, 从而减少 保护区与社区的矛盾冲突。然而, 针对保护区与周 边社区的利益共享还有很多障碍, 例如当资金决策 权掌握在保护地管理者或资金捐助者手里时, 通常 社区的需求会被忽略。

(3)保护地管理成本共担机制。大多数保护地倾 向于单纯地募集资金, 而没有意识到可以与其他机 构分担管理成本, 从而减轻保护地管理机构的压 力。加拿大、澳大利亚等国家政府的保护地管理机 构将一部分权力和责任下放给社区、环保NGO或其 他社会团体，通过授权代理方式或者联合管理模式 鼓励其他群体来分担管理成本以及管理责任, 使保 护地管理的有效性得到改善。当然, 这种成本共担 机制经常需要建立在强制性的制度基础之上。此外, 成本分担的比例、权力和责任等都必须清晰地界定 出来, 必要时可通过出台相关的法律来保障。

（4）金融交易、信用贷款和生物多样性企业基 金。在过去 20 年里, 很多政府已经调整了环境和自 然资源的税收和补贴制度来支持保护地的生物多 样性保护。生物多样性补偿(抵消)最早开始于 20 世 纪70年代美国的“湿地补偿银行”, 实行的是第三方 补偿机制, 就是说有湿地补偿责任的当事者, 并不 是直接向美国湿地主管部门进行补偿, 而是通过 “湿地补偿银行”来购买再建或人工恢复的湿地来实 施补偿。生物多样性企业基金是向投资于生物多样 性保护和可持续利用的商业投资者提供长期的资 本，这里的商业投资者一般是指参与生物多样性保 护活动的中小型企业, 例如从事生态旅游、可持续 林业、野生木材产品的采集和加工的企业等。

\section{3 基于保护地产品和服务的市场收费}

资源使用者付费、旅游收费和生态系统服务付 费都是基于保护地受益者的支付意愿的一种市场 收费。资源的使用者付费是许多地方保护地资金的 一个核心组成部分, 但过去许多保护地的产品和服
务定价太低甚至可以免费获得，这就需要建立资源 有偿使用制度和进行价格调控等。旅游者付费, 既 能为保护地带来创收, 也有助于控制游客数量。

生态系统服务付费(payment for ecosystem service)是一种基于生态系统服务的交易手段, 前提是 要明确生态系统服务的提供方(卖方)和受益方(买 方), 通过自愿交易, 促进双方更加公平地分担成本 和分配效益。所提供的生态系统服务类型包括碳汇 功能、湿地和流域保护功能、物种和栖息地的保护 等, 但有时很难明确所提供的生态系统服务种类及 其服务价值, 例如许多保护地为河流下游城镇提供 了非常有价值的水源保护服务, 但大多数情况下无 法估计出其具体价值(Pagiola et al., 2002)。

针对上述几种市场收费手段的应用前景和不 足之处, 国际上已经有相关研究(Emerton et al, 2006)，这里不再赘述。

\section{5 保护地融资机制的发展趋势}

\subsection{6 种创新融资机制}

未来融资机制的创新将更多地依托于财政、金 融、市场、贸易等手段，包括税、补贴和信用体系; 碳交易或者其他生态系统服务付费; 寻找新的捐助 者(例如大型企业、慈善家、其他政府机构或者税收 共享); 建立当地利益相关者的成本分担和收益共 享机制(包括私人土地所有者和当地社区); 改善大 的政策和市场条件(例如取消环境有害行为的津贴, 创立积极的激励机制); 融资和管理责任的下放(例 如下放给NGO、当地社区、个人或企业)等。

经济合作与发展组织(OECD)针对生物多样性 的融资机制提出了6种创新融资机制，包括：(1)环 境财政改革; (2)生态系统服务付费; (3)生物多样性 补偿(抵消); (4)绿色产品市场; (5)利用气候变化资 金对生物多样性投资; (6)通过国际发展援助对生物 多样性投资(OECD, 2013)。其中特别强调了利用减 缓和适应气候变化的双边或多边项目资金对生物 多样性投资, 这也是保护地未来融资的一个重要 渠道。

\subsection{6 种保护地创新融资机制对于我国的适用性}

(1)环境财政改革。环境财政改革包括引入自然 资源使用税，取消环境有害产品的补贴，引入新的 产品税和使用者付费, 调整其他税费等(Emerton et $a l .$, 2006), 对于拓宽保护地投资渠道有重要意义。 
对于我国这样一个人口大国, 税基的庞大会使得生 态税成为一个非常重要的资金来源。是重新设立一 个税务名目对直接和间接消费保护地产品(服务)的 个人和企业征收生态税, 还是从现有的个人所得税 中抽取一定比例作为生态税? 需要进一步的政策 考量和设计。

(2)生态系统服务付费。近年来很多国家已经在 不同的生态系统服务领域开展了PES试点, 越来越 多的证据表明生态系统服务付费可以作为对保护 地附近土地所有者进行补偿的一种有效机制。PES 并不等同于损害性的生态补偿, 也不同于我们常说 的针对正的外部性的补偿, 它存在明确的生态服务 提供者和服务的购买者, 否则就无法进行交易, 比 如河流流域的上、下游之间就可能存在这种交易。 特别值得一提的是PES机制需要明晰的产权结构, 从而确定“买方”与“卖方”。而且, 实施PES通常需要 在技术能力方面做大量的投入, 例如长期的背景值 调研、利益方谈判、监测、评估等, 目前我国在这 个领域的工作基础还比较薄弱, 未来有待进一步 加强。

(3)生物多样性补偿(抵消)。这也是保护地领域 的一个新的市场融资渠道。例如某企业在保护区的 实验区内从事资源考察或勘探等活动, 占用了某块 林地(湿地、草地), 那么该企业就可以通过购买面积 和保护价值相当的人工恢复湿地或林地, 作为对生 物多样性的一种补偿。但我国目前人工恢复湿地的 技术能力不足, 短时间无法市场化, 笔者认为当前 我国还不具备利用这种融资渠道的条件, 但这个领 域很有发展前景。

(4)绿色产品市场。自然保护区周边区域得天独 厚的自然地理条件孕育出来的绿色产品, 如果获得 相应的绿色、有机产品、可持续等标签认证, 其价 格就会稍高于同类产品, 既能为保护区带来额外的 经营收入, 也能引导消费者选择绿色消费方式, 还 可以为保护区内及周边居民带来新的就业机会, 可 谓一举多得。目前我国少数自然保护区已经开发了 绿色产品, 比如福建武夷山自然保护区的有机茶 叶、西洞庭湖自然保护区的有机渔业产品等。

(5)利用气候变化资金。近年来, 我国已经通过 清洁发展机制下的森林碳汇项目为林业的发展募 集了一定的资金，但由于种种原因目前这方面的项 目数量还相对太少。截至2013年底, 中国林业碳汇
项目获得气候变化框架委员会下的执行委员会 (EB)注册的项目数仅 4 个, 而获得签发的项目数仅 有 2 个。未来应该进一步加大碳汇项目的开发, 并将 其收益更多地用于林业类型自然保护区的管理。

(6)通过国际发展援助。除了联合国开发计划 署、世界银行等国际机构针对生物多样性保护的发 展援助项目, 很多国家在华的发展援助合作机构如 英国的国际发展部、澳大利亚驻华使馆发展合作处 (澳发署)、瑞士发展合作署等，也通过提供资金和技 术支持，与中方在生物多样性保护、气候变化适应 和自然保护区能力建设等领域开展了很多合作。未 来需要继续保持与这些国际发展援助机构的密切 联系，积极寻找在自然保护区管理领域合作的 契机。

\section{6 我国自然保护区融资和资金使用现状及 问题}

根据《2014中国环境状况公报》(http://www. zhb.gov.cn/gkml/hbb/qt/201506/t20150604_302942.htm), 截至2014年底, 全国共建立各种类型、不同级别的 自然保护区 2,729 个, 总面积约 14,699 万公顷。其中 陆域面积 14,243 万公顷, 占全国陆地面积的 $14.84 \%$, 超过 $12 \%$ 的世界平均水平。以自然保护区为主体的 生物多样性就地保护网络已经基本形成。自然保护 区的建立和发展，有效保护了我国70\%以上的自然 生态系统类型、 $80 \%$ 的野生动物和 $60 \%$ 的高等植物 种类以及重要自然遗迹(高军等, 2012)。但目前各类 自然保护区几乎都面临着经费短缺的困扰, 限制了 自然保护区的进一步发展(王富有等, 2008)。因此了 解我国自然保护区的融资和资金使用现状, 发现目 前存在的主要问题，借鉴国际经验，对保护区的可 持续发展乃至国家的持续发展都具有非常重要的 意义。

\section{1 融资渠道}

我国自然保护区的资金来源总的来说分为以 下三大类:

(1)财政渠道。这是最主要的资金来源, 具体包 括本级财政经常性预算和上级财政一般性转移支 付、中央财政专项资金、地方政府专项资金、专项 基金(例如森林生态效益补偿基金)等。虽然我国自 然保护区采用分级管理, 但从法律文件上看, 目前 无论是国家级还是地方级自然保护区的经费都主 
要由地方政府承担。如《中华人民共和国自然保护 区条例》(以下简称《自然保护区条例》)第二十三 条“管理自然保护区所需经费，由自然保护区所在 地的县级以上地方人民政府安排。国家对国家级自 然保护区的管理, 给予适当的资金补助”。可以看出 这里对中央政府对国家级自然保护区的资金责任 描述得较为模糊。特别是国家“十五”计划(20012005年)以前, 中国各级自然保护区管理机构(包括 国家级)主要的资金来源是地方财政资金。由于中 央拨款机制的缺失，一些经济相对落后地区的地 方政府又无力投入，导致很多自然保护区都处于 经费极度短缺的状态。进入 “十五”计划以后, 这种 情况逐渐得到缓解，中央财政资金(主要以项目形 式)在自然保护区的资金来源结构中所占比例显著 增大。

(2)一些双边或多边的国际援助项目。例如全球 环境基金(GEF)迄今已在中国近 40 个自然保护区开 展了 GEF援助社区共管共利机制的项目 (王蕾, 2010), 此外还有来自国际组织、环保NGO、社团等 各类社会团体的捐赠。当前我国的这种捐赠规模与 发达国家相比较小而且主要来自境外资金, 其中一 方面原因是国内环保类NGO、公益基金会等团体发 展还相对不成熟, 经济实力也相对较弱; 另一方面 也是因为自然保护区的管理者对于保护区融资机 制的探索创新还比较缺乏, 过度依赖传统的财政渠 道; 第三个原因就是整个社会公众的生态保护意识 还相对不足。WWF荷兰分会约 $70 \%$ 的荷兰国民都是 该基金会的会员，他们每年都会缴纳一定的会员 费，除了用于支持荷兰本土的保护项目，还支持着 像中国、印度等发展中国家的一些保护项目。

(3)保护区经营性收入和服务型收费(例如门票 费用、讲解费用、餐饮和交通服务收费等)。存在经 营收入的自然保护区，有的是保护区管理局下属的 旅游公司或其他企业在经营，也有承包给社会上的 私营企业团体来经营。而那些并没有开展资源利用 和生态旅游活动的保护区则没有这部分收入。

虽然财政渠道目前是我国自然保护区最主要 的资金来源，但是在我国当前财政投入力度有限而 保护区数量和规模又较大的背景下, 市场渠道和社 会渠道的融资就显得越发重要，而且这类资金的使 用灵活, 能弥补财政投资的空白, 例如通过市场渠 道筹资来支付野生动物损害赔偿。

\section{2 融资和资金使用中存在的问题}

(1)资金来源结构不合理。我国自然保护区的资 金来源中财政渠道(尤其是中央财政)和社会渠道所 占比例过小。例如2003年, 在我国林业系统的保护 区资金来源中，中央财政占 $9 \%$ ，地方财政投资占 $35 \%$ ，其余为林业系统投资(18\%)、银行贷款 $(11 \%)$ 及其他来源 (主要是保护区开展经营活动的收入, $26 \%$ )，公益捐赠仅占 $1 \%$ (苏杨, 2004)。我国各级自然 保护区的人头费、事业费以及部分补偿费(如野生动 物危害赔偿费)主要由同级别的地方政府提供，只 有部分国家级自然保护区能申请到由国家主管部 门提供的基础设施建设费用补助及专项经费(王蕾, 2010)。当然，“十五”计划之后，中央财政拨款在个 别国家级自然保护区已经成为最主要的资金来源, 但笔者认为应该从法律上明确中央财政对国家级 自然保护区的资金来源承担主要责任，这也符合经 济学上“谁受益、谁付费”的原则。例如笔者实地调 研了东洞庭湖国家级自然保护区，了解到该保护区 目前没有固定的中央财政来源, 主要依靠申请国家 的项目资金，但这些项目并不是每次都能申请到， 周期往往只有 3-5年, 其中唯一固定的资金来源就 是每年来自岳阳市的财政拨款。

(2)资金规模满足不了实际需求，支出结构不合 理。自然保护区的资金支出可以划分为基本建设支 出和事业费支出两大块。其中基本建设支出包括保 护工程、科研监测、宣教、基础设施、生态旅游、 社区共管、多种经营和其他费用8项; 事业费支出包 括职工工资和福利、社会保障、季节性临时工和其 他办公费用等(王蕾，2010), 目前仍然存在较大缺 口。例如 2015 年笔者在实地调研中了解到, 目前东 洞庭湖国家级自然保护区可用资金不到实际需求 的 $50 \%$ 。目前我国自然保护区的资金使用中，因资 金总量过少，虽然有很大比例用于人头费即人员工 资和各种福利补贴，但很多保护区管理局以及基层 管理站的员工的待遇和福利在当地仍处于较低的 水平。由于经费短缺的压力, 一部分保护区过分重 视自行创收活动, 因而出现重经营轻管理的情形, 必然影响到保护目标的实现。

另外一方面，在资金投入非常有限的背景下， 也存在着资金支出结构不合理和使用效率不高的 问题，很多保护区在资金安排上先保员工工资，再 安排基础设施建设, 接着才考虑日常管理需要, 最 
后再考虑补偿，即资金没有优先用到保护区的核心 保护业务。例如北京的松山国家级自然保护区，自 2005年起保护区每年可固定从国家财政部门获批 100 万元的能力建设经费, 但这些投入很大程度上 是用来进行恢复性基础设施建设，保护区科研、监 测、管护等保护区最基础的工作资金仍然存在很大 缺口(陈学琴等, 2007)。

(3)周边社区缺乏补偿和收益共享。保护区周边 社区与保护区的冲突根源就是成本效益的不对等, 周边居民承担了失去土地、被迫放弃传统生计方 式、发展方式受限等损失和机会成本, 有的居民还 要蒙受保护动物损害房屋、庄稼、牲畜等损失。然 而，很多保护区在前期融资计划和后期资金的使用 分配上都没有优先考虑周边居民的补偿问题，而且 很多保护区的营利创收活动也并没有优先考虑将 工作机会给当地居民, 没有建立起保护区与周边社 区之间的合作共赢机制, 严重影响保护区的可持续 发展。

\section{7 针对资金机制改革创新的几点建议}

\section{1 融资渠道}

(1)加大中央和地方财政投入力度, 明确中央财 政在国家级自然保护区管理经费中的主导地位。我 国当前处于从计划经济过渡为市场经济的转型期, 短期内不可能完全依靠市场渠道来筹集保护区的 资金，过度依赖境外捐助也存在很大风险。笔者认 为应该从法律上保障中央政府和地方政府将保护 区纳入常规财政预算项目。应明确规定由中央政府 负担国家级自然保护区的主要经费投入, 尤其是对 于那些需要严格禁止资源开发利用的自然保护区, 要加大财政资金投入的比重, 并将自然保护区技术 与管理人员纳入公务员系列, 使国家级自然保护区 的经费得到根本保障。

对保护区设立和管理中那些承担了一定间接 成本和机会成本的周边社区给予经济补偿。关于补 偿资金的来源，笔者认为在当前市场环境尚不成熟 以及民间组织力量相对薄弱的背景下, 短期内还应 该保证以政府财政支出为主。从补偿的形式上看, 应努力创造造血式的发展援助型补偿, 将补偿转化 为地方生态保护或提升地方发展能力的项目, 应该 充分发挥社会公益组织和国际保护性 $\mathrm{NGO}$ 组织的 技术力量, 借鉴他们在社区发展项目中的经验。
(2)尽快建立或完善基于保护地产品和服务的 市场收费和交易制度。党的十八大已经特别提出要 落实资源有偿使用制度。对于自然保护区的产品(服 务)应当遵循使用者付费的原则，一方面限制使用 者的过度拥挤, 另一方面也可以通过这一收费向承 担间接保护成本和机会成本的群体进行补偿。

生态旅游是很多国家保护地融资的一个重要 手段。笔者认为一些具备开展生态旅游资源的自然 保护区在条件成熟时应适当发展生态旅游服务, 并 尽量让经营活动的收益惠及周边社区居民，从而实 现保护区带动周边发展、周边发展反哺保护这样一 种可持续状态。这里所说的生态旅游经营收入并不 是指简单的门票费用，而且笔者也不建议门票定价 过高, 主要指的是生态旅游经营者所提供的餐饮、 娱乐、交通等商业服务的收费。此外，针对保护区 内的生态旅游服务的经营主体, 笔者建议效仿美国 国家公园的特许经营制度，保护区管理局对经营活 动进行监管但不直接参与, 从而减少腐败行为 滋生。

生态系统服务付费在我国还处于初级阶段。基 于国际上生态服务付费的经验, 当资源权属相对明 晰、生态系统服务明确、服务的提供者和受益者相 对明确且数量较少、交易成本相对较低时, 可开展 这方面的试点工作，促成双方签署生态服务买卖的 协议。签署协议的双方可以是单个或多个社区团 体、私人企业、社会团体，也可是地方政府。例如， WWF在赤水河流域开展的流域生态系统服务付费 的试点项目, 由下游酒厂出资购买上游通过改变种 植结构和产业模式等进行植被保护和维持良好水 质的服务。

同时，也应该积极争取国际上交易项目的资金 援助, 例如减缓气候变化的森林碳汇交易项目。此 外, 对于部分保护区内及周边的生态友好产品, 可 通过生态标签认证等渠道促进贸易, 既可以为保护 区创收，也可以带动周边社区的可持续发展。例如 西洞庭湖国家级自然保护区的青山垸已经通过申 请有机渔业认证。保护区周围社区的补偿也应该纳 入保护区管理总成本, 如通过支持社区替代生计的 发展来弥补其发展成本和机会成本。

(3)充分开发和利用各种社会融资渠道。积极申 请生物多样性领域的双边/多边援助项目及国际金 融组织优惠贷款项目, 积极争取 GEF等国际保护型 
基金和国际环保NGO资助的保护项目，利用境外资 金提升我国自然保护区的能力建设水平; 同时积极 争取国内具有较强社会责任感的企业、公益性的社 团和基金会等团体的国内资金支持。

(4)通过治理模式改革更好地利用外部资金，促 进保护区成本分担和效益共享。治理模式对于保护 区保护目标的实现具有关键作用, 决定了相关成本 效益分担，是预防或解决社会冲突的关键，影响着 来自社会、政治和财政上的支持(Borrini-Feyerabend et al., 2013)。世界自然保护联盟、世界保护地委员 会(WCPA)等国际组织将保护地的治理类型分为 4 大类: 政府治理，联合治理或共同治理，私人治理， 土著和当地社区自治。

共同治理模式在很多发达国家已有成功实践, 少数发展中国家也开始尝试采用。这种模式尽可能 兼顾各方权益并充分考虑各方话语权, 对于我国自 然保护区资金机制创新具有很大的借鉴意义。我国 近期可以选择条件成熟的保护区进行政府+社区(还 可能包括生态旅游企业、NGO、科研机构等)联合 治理模式的试点，从而将企业资金、社会公益资金 引入自然保护领域, 形成一个多方治理的共赢模 式, 从而减轻政府财政负担。此外, 政府治理模式 中，政府委托第三方治理的模式对我国也有一定的 借鉴意义, 特别是当前政府从全能政府向服务型政 府转变, 应该充分调动社会各界人士参与自然保护 区管理，去解决自然保护区的资金短缺问题和各利 益方权责分配的公平问题。笔者认为在一些面积较 小、级别较低的小型自然保护区例如县级自然保护 区，可以进行这一模式的试点。

\section{2 针对保护区资金使用和分配的建议}

(1)健全保护区财务管理制度，合理使用和分配 资金。要从立法上明确自然保护区的财务管理制度, 每年的预算计划要报上级主管部门审批并严格执 行, 在保障保护区工作人员基本薪酬福利的前提 下，要将剩余资金包括经营收入优先用于核心保护 业务的投资和周边社区的生态补偿上，禁止将保护 工作资金挪用到保护区内非保护需求的基础设施 建设和其他非核心保护业务领域。

(2)加强保护区资金的监管和信息公开。要加强 资金的监管包括上级主管部门的行政监管和社会 的與论监督, 保护区每年的预算计划和年终财务报 告都要向社会公开, 针对社区的补偿性资金也要向
居民公开补偿依据和标准。

(3)建立保护区与周边社区收益共享机制。构建 保护区与周边社区的共同治理模式，赋予当地居民 优先的资源开采利用、生态旅游经营活动等权利或 者使其享有一定的收益权，实现保护区与社区的合 作共赢式发展。

\section{参考文献}

Adrian P (2000) Financing Protected Areas. IUCN Publications, Gland, Switzerland

Balmford A, Bruner A, Cooper P, Costanza R, Farber S, Green RE, Jenkins $M$, Jefferiss P, Jessamy V, Madden J, Munro K, Myers N, Naeem S, Paavola J, Rayment M, Rosendo S, Roughgarden J, Trumper K, Turner RK (2002) Economic reasons for conserving wild nature. Science, 297, 950-953.

Borrini-Feyerabend G, Dudley N, Jaeger T, Lassen B, Pathak Broome N, Phillips A, Sandwith T (2013) Governance of Protected Areas: From Understanding to Action. IUCN Publications, Gland, Switzerland.

Bruner A, Gullison R, Balmford A (2004) Financial costs and shortfalls of managing and expanding protected area systems in developing countries. BioScience, 12, 1119-1126.

Castro G, Locker I (2000) Mapping Conservation Investments: An Assessment of Biodiversity Funding in Latin America and the Caribbean. World Resources Institute Publications, Washington, DC.

Chape S, Harrison J, Spalding M, Lysenko I (2005) Measuring the extent and effectiveness of protected areas as an indicator for meeting global biodiversity targets. Philosophical Transactions of the Royal Society of London Series B: Biological Sciences, 60, 443-455.

Chape S, Blyth S, Fish L, Fox P, Spalding M (2003) United Nations List of Protected Areas. IUCN Publications, Gland, Switzerland.

Chen XQ (陈学琴), Nie H (聂华)(2007) SWOT analysis of Beijing Songshan National Nature Reserve. Journal of Anhui Agriculture Science (安徽农业科学), 35, 4264-4266. (in Chinese with English abstract)

Cousins JA, Sadler JP, Evans J (2010) The challenge of regulating private wildlife ranches for conservation in South Africa. Ecology and Society, 15, 28.

Diefendorf S, Barbaria L, Roberts N, Fox F (2012) International Guidebook of Environmental Finance Tools. UNDP Publications, New York.

Dudley N (2008) Guidelines for Applying Protected Area Management Categories, pp. 24-34. . IUCN, Gland, Switzerland.

Emerton L, Bishop J, Thomas L (2006) Sustainable Financing of Protected Areas: A Global Review of Challenges and Options. IUCN, Gland, Switzerland and Cambridge, UK.

Ervin J (2003) Protected area assessment in perspective. BioScience, 53, 819-822.

Gao J (高军), Jiang MK (蒋明康), Xu HG (徐怀谷) (2012) 
Analysis of management costs based on attributes of a nature reserve. Journal of Ecology and Rural Environment (生 态与农村环境学报), 1(28), 98-102. (in Chinese with English abstract)

Hockings M, Stolton S, Dudley N, Leverington F, Courrau J (2006) Evaluating Effectiveness: A Framework for Assessing Management Effectiveness of Protected Areas. IUCN Publications, Gland, Switzerland.

Landrum Ney C (2005) Entrepreneurism in America's State Parks. The George Wright Forum, 22, 27-31.

Lapham N, Livermore R (2003) Striking a Balance: Ensuring Conservation's Place on the International Biodiversity Assistance Agenda. Conservation International, Washington, DC.

Lewandrowski J, Darwin R, Tsigas M, Raneses A (1999) Estimating the costs of protecting global ecosystem diversity. Ecological Economics, 29, 111-125.

Molnar A, Scherr SJ, Khare A (2004) Who Conserves the World's Forests? A New Assessment of Conservation and Investment Trends. Forest Trends, Washington, DC.

OECD (2013) Scaling-up Finance Mechanisms for Biodiversi- ty. OECD Publishing, Paris.

Pagiola S, Bishop J, Landell-Mills N (2002) Selling Forest Environmental Services: Market-Based Mechanisms for Conservation and Development. Earthscan, London,

Pang SJ (庞少静) (2004) Environmental problems and strategy towards ecological tourism development. Environmental Protection (环境保护), 9, 28. (in Chinese with English abstract)

Su Y (苏杨) (2004) Harmonized development of nature reserves and their ambient communities in West China. Rurual Eco-environment (农村生态环境), 1(20), 6-10. (in Chinese with English abstract)

Wang FY (王富有), Chen JH (陈建华) (2008) The financial sources of the nature reserves. Journal of Northwest Forest$r y$ University (西北林学院学报), 23, 226-228. (in Chinese with English abstract)

Wang L (王蕾) (2010) Scheme Study on Ecological Efficiency Allowance of Nature Reserves (自然保护区生态效益补助 方案研究). $\mathrm{PhD}$ dissertation, Beijing Forestry University, Beijing. (in Chinese with English abstract)

(责任编委: 薛达元 责任编辑: 时意专) 